\title{
Developing an Assessment-Link Mobile Application: A Catalyst for Pre-service Biology Teachers to Analyse Cognitive Test
}

\author{
Endang Susantini ${ }^{*}$, Suyatno ${ }^{1}$, Wasis $^{1}$, Haniza H. M. Zain ${ }^{2}$, and Mohamad T Borhan ${ }^{2}$ \\ ${ }^{1}$ Biology Department, Faculty of Mathematics and Natural Sciences, Universitas Negeri Surabaya,Indonesia \\ ${ }^{2}$ Universiti Pendidikan Sultan Idris, Malaysia
}

\begin{abstract}
This study aimed to develop a valid android-based Assessment-Link application to help preservice biology teachers practice skills of biology cognitive test questions based on Revised Bloom's Taxonomy. The development procedure of the application used Kemp, Morrison, and Ross' instructional design consisting of nine stages namely instructional problems, learner characteristics, task analysis, instructional objectives, content sequencing, instructional strategies, designing the message, development of instruction, and evaluation instruments. In this study, there were six biology learning assessment experts from Indonesia and Malaysia universities involved in assessing the quality of the Assessment-Link application. The application quality assessment was carried out on three aspects including content, design, and engagement. This result was in a form of an Assessment-Link application product that contained several features namely tutorial, introductory menus, Revised Bloom's Taxonomy materials, materials of criteria and how to write good test questions, exploration, interactive quiz, and task. The validity test result showed that all aspects of the assessment were in a very good category. Therefore, the Assessment-Link application developed was valid and able to be used to prepare pre-service biology teachers in analysing biology test questions based on Revised Bloom's Taxonomy.
\end{abstract}

Keywords: Biology teachers, Assessment-Link application, Revised Bloom's Taxonomy

\section{Introduction}

Assessment is an integral part of learning process used to determine whether learning objectives are achieved. To carry it out, tools or instruments are required, one of which is a test instrument based on the revised Bloom's taxonomy. Learning indicators in revised Bloom's taxonomy combine the domain of cognitive process and knowledge [1]. Categories and sub-categories in the revised Bloom's taxonomy have also changed from nouns to verbs and at the cognitive level category [1]. The fifth cognitive level, which was originally synthesized, is removed and replaced by evaluation, while the sixth cognitive level, which was originally evaluation, is replaced by creation that represents the highest level of Bloom Revised Taxonomy.

The use of revised Bloom's taxonomy makes the meaning of learning objectives more dynamic. Crowe \& Wenderoth's [2] research shows that Bloom's taxonomy helps teachers organize questions at a higher cognitive level. Kusuma \& Rinanza [3] also show that the use of the template method can generate questions that are in accordance with the revised Bloom's taxonomy with an accuracy of $81.65 \%$. However, there has been reported that teachers and pre-service biology teachers still face difficulties in determining the cognitive level of test questions based on revised Bloom's taxonomy. This is because most teachers are not familiar with revised Bloom's taxonomy [4]. The ability to analyze indicators when compiling and classifying the cognitive level of questions is vital in achieving accurate cognitive level [5]. Hence it is pertinent for teachers and pre-service teachers to master the cognitive level of revised Bloom's taxonomy.

In the era of Industrial Revolution 4.0, one of the technologies that can be utilized in developing learning media to train biological test analysis skills is an android-based mobile application. Android applications can support any learning process because the information presented is easily accessible anytime and anywhere. This is in accordance with current learning needs of distance learning due to the closure of educational institutions to avoid the transmission of Covid-19 [6]. The use of learning applications will potentially handy for pre-service teachers to learn analysing biology tests based on the revised Bloom's taxonomy.

Based on the aforementioned description, this study aimed to develop an application named AssessmentLink that can train the skills of analysing biology tests

\footnotetext{
* Corresponding author : endangsusantini@unesa.ac.id
} 
based on Revised Bloom's Taxonomy. The present study also depicted the application's quality.

\section{Literature review}

\subsection{Android-based learning application}

Technology development in Industrial Revolution Era 4.0 has brought changes towards the digitization of information, including learning media. Utilization of technology in learning can be undertaken to help deliver materials to students easily [6]. If teachers are able to use digital technology in the form of learning applications, a learning environment might also integrate various digital tools such as multimedia, audio, and interactive media to help teach certain materials [7]. One of the well-known learning digital tools is an Android-based learning application.

Android is the world's most popular operating system for mobile and tablet devices. Its open, free and easily available in nature makes Android easy to learn, modify, improve, disseminate, and access for free [8]. It is equipped with various applications that can be designed and accessed [9], including applications applied in education domain. Android-based learning application can be developed to support learning process [10]. This is due to the fact that many students are accustomed to using smartphones and internet, so that the condition is relevant with the implementation of digitized learning process [11]. Consequently, students get easier learning access regardless times and places [11].

The application of android-based learning can improve the quality of learning process [7], [12-13]. The use of mobile learning contributes to inquiry-based laboratory activities to improve the user's science process skills [7]. Learning using an android-based virtual-lab can increase students' learning independence [12]. Android-based applications also could increase the student's motivation [13]. In addition, android-based learning also increases the mobility of students, so that learning is more flexible without time constraints [14], [16].

The ability of the application to increase the effectiveness of learning process depends on its supporting interaction feature [17]. An effective application has several criteria, including 1) the age range of the user, content and features presented must be in accordance with the chronological age of the user, not only their developmental age [18]; 2) feature design, application layout must be clear and consistent, easy to navigate, no distracting features, easy to understand information presentation, integrating various media (auditory, visual), and representation format (verbal, nonverbal) that aim to reduce the cognitive burden of users due to differently processed in various cognitive areas [19-20]; 3) the relationship with the curriculum, the application is developed based on curriculum standards, the content in accordance with the user's abilities, and improving academic abilities and certain skills [19]; 4) feedback, the application provides feedback in a simple, clear, and does not create a reinforcing effect that allows the user to intentionally make mistakes so that they can see the feedback [20]; and 5) student motivation, the application can increase user's interest in the topic learned [19].

\subsection{Revised Bloom's Taxonomy}

In 1949, Benjamin S. Bloom proposed his thoughts on a cognitive taxonomy known as Bloom's taxonomy. Bloom's taxonomy categorizes a person's cognitive abilities into six levels, namely knowledge, comprehension, application, analysis, synthesis, and evaluation. However, experts encounter some weaknesses and limitations in the application of Bloom's taxonomy [21-22]. One of them is the assumption that cognitive processes are the only behavioural dimension, ranging from simple to complex dimensions. Hence, a group of experts proposed a revision of Bloom's Taxonomy, known as the revised Bloom's Taxonomy. Research [23] related to the study of acceptance of the revised bloom taxonomy shows that the revised bloom taxonomy is useful and can be applied in learning.

Revised Bloom's taxonomy emphasizes the use of verbs and nouns to name categories and sub-categories. Revised Bloom's taxonomy combines two domains namely the cognitive process and knowledge. The cognitive process represents an activity that takes place continuously, which can improve cognitive abilities at a more complex level starting from remembering $(\mathrm{C} 1)$ to creating (C6). Meanwhile, the domain of knowledge represents variations in forms of knowledge, ranging from concrete (factual) knowledge to abstract (metacognitive) forms.

Revised Bloom's taxonomy makes easier for teachers to define learning objectives, thus, it makes students aware of what they are learning and focused on achieving learning objectives [24-25]. Therefore, teachers and pre-service teachers are advisable to wellverse the revised Bloom's taxonomy in order to determine learning objectives as well as assessment form to measure the achievement of the goals.

\subsection{Analysing skills and their categories}

Analysing skills include thinking skills on the cognitive domain of Revised Bloom's Taxonomy at the fourth level (C4). Analysing skills are one's skills in breaking down a phenomenon into sub-focus parts and determining how these sub-focuses relate to each other and to the overall structure or phenomenon [1]. Table 1 shows the analytical skills that will be used in this study.

Table 1. Analysing skills along with categories and examples

\begin{tabular}{|c|c|}
\hline Category & Examples on Biology Topics \\
\hline $\begin{array}{c}\text { Differentiating } \\
\text { (Differentiating, } \\
\text { determining) }\end{array}$ & $\begin{array}{c}\text { Distinguishing relevant materials } \\
\text { from those that are not, for } \\
\text { example, distinguishing living } \\
\text { things based on their characteristics }\end{array}$ \\
\hline
\end{tabular}




\begin{tabular}{|c|c|}
\hline $\begin{array}{c}\text { Organizing } \\
\text { (Organizing, } \\
\text { disconnecting, } \\
\text { connecting, } \\
\text { integrating, } \\
\text { deciphering, } \\
\text { structuring) }\end{array}$ & $\begin{array}{c}\text { Determining the role of an } \\
\text { element/concept in a particular } \\
\text { structure/phenomenon, for } \\
\text { instance, collecting evidence to } \\
\text { support evolution }\end{array}$ \\
\hline $\begin{array}{c}\text { Attributing } \\
\text { (Correlating, } \\
\text { deconstructing) }\end{array}$ & $\begin{array}{c}\text { Determining point of view, bias, } \\
\text { value, or purpose of a concept, for } \\
\text { example, determining an ecological } \\
\text { point of view related to } \\
\text { reclamation }\end{array}$ \\
\hline
\end{tabular}

Adapted from Anderson, et al. (2001)

\section{Methods}

This study used a development research design in the field of education. The main product of this study was Android-based Assessment-Link application. The study referred to Kemp, Morrison, and Ross' instructional design [26] consisting of nine elements (see Figure 1).

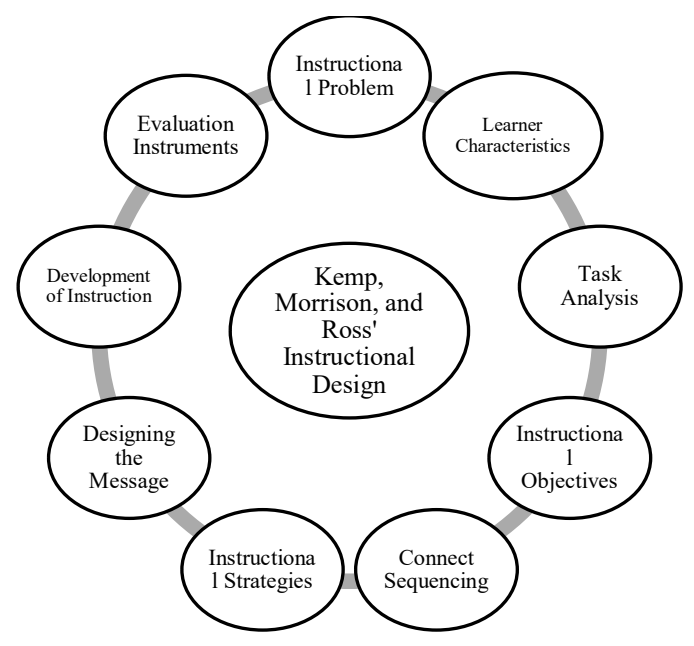

Fig. 1. Kemp, Morrison, and Ross' Instructional Design [26]

The instructional problem stage was carried out to identify the problems why Assessment-Link application needed to be developed. The learner characteristics was carried out to determine student's characteristic obtained through a student needs questionnaire distributed to 36 biology education students. The task analysis referred to an activity where the researchers identified the content of materials to be included in the Assessment-Link application and analysed the tasks and exercises to achieve the objectives. In the element of instructional objectives, instructional objectives were specified for the development of Assessment-Link application. In the content sequencing stage, the content of the material used in the application was sorted, including Bloom's taxonomy materials before and after revision, characteristics of good test questions, examples of biology test questions at various cognitive and knowledge levels, and quiz questions. In connection with instructional strategies, the design of features and guidelines for using the application were carried out so that students could achieve the expected goals through the application utilization. In regard to designing the message, the preparation of the application design was carried out starting from the content and order of the materials and application design. In the development of instruction element, the development was carried out in a form of an android-based application. In the evaluation instrument stage, a validation instrument was developed to assess the feasibility of the application in achieving the formulated objectives.

\subsection{Data collection and analysis techniques}

Data were obtained by using questionnaire on the needs of Assessment-Link application and the AssessmentLink application validation sheet that were administered via online using Google form. The application needs questionnaire consisted of 18 items, while the validation sheet consisted of 58 items that were divided into three aspects namely content, design, and engagement aspects adapted from Lee and Cherner [27]. The validation questionnaire was filled out by six biology learning assessment experts from Indonesia and Malaysia universities. Experts were asked to install and experience the Assessment-Link application before giving an assessment. The experts were invited to response on the item using 4-point Likert Scale.

The data of need analysis and application validation obtained were analysed using descriptive statistics. The application validation data used score intervals. Each answer criterion was given a score of 1-4 with the following score criteria: very good (4), good (3), sufficient (2), and Insufficient (1). Afterward, the maximum and minimum scores were determined by calculating the interval distance using the following formula:

Interval distance $=\frac{\text { max.score }(4) \times \text { min.score }(1)}{\text { number of class intervals }(4)}$

Based on this formula, the interval distance was 0.75 . Table 2 shows a classification based on the average score of the Assessment-Link application validation results.

Table 2. Score interpretation based on the average score

\begin{tabular}{|c|c|c|}
\hline No. & Average Scores & Interpretation \\
\hline 1 & $1.00-1.75$ & Insufficient \\
\hline 2 & $1.76-2.50$ & Sufficient \\
\hline 3 & $2.51-3.25$ & Good \\
\hline 4 & $3.26-4.00$ & Very Good \\
\hline
\end{tabular}

\section{Findings and discussion}

Based on the student needs questionnaire for androidbased applications completed by 36 students, 35 students $(97.2 \%)$ used gadget to study because they were easy to access, more practical to use, and were already accustomed to using it. This was in accordance 
with [11] that, in the current digital era, students had a habit of using gadgets and internet. It also showed that gadget could be utilized to support the learning process [28-29].

Regarding the mastery of the revised Bloom's taxonomy, 10 students $(28.6 \%)$ already knew what the revised Bloom's taxonomy was and 26 students (74.3\%) did not know and expressed interest in studying the revised Bloom's taxonomy. 31 students $(93.9 \%)$ found difficulties in analysing biology test questions, including analysing cognitive and knowledge domains based on revised Bloom's taxonomy. All students expressed their interest in studying the revised Bloom's Taxonomy and how to analyze biology test questions based on the Revised Bloom's Taxonomy. Students also expressed the needs to develop an android-based application that could help them analyse biology test questions based on the revised Bloom's taxonomy.

Based on the results of the analysis, an androidbased learning application was designed known as Assessment-Link. The application contained starting interface containing the background for which the application was designed. The application also contained materials related to the comparison of Bloom's taxonomy before and after the revision, characteristics of good test questions, and examples of biology test questions at various cognitive and knowledge domains based on the revised Bloom's taxonomy. In addition, the application was also equipped with several features including 1) Exploration that was integrated with websites related to the revised Bloom's taxonomy, 2) Tutorials that contained guidelines for using the application, 3) Interactive quizzes that contained exercises to analyse cognitive and knowledge domains of 15 biology questions, and 4) Tasks that were integrated with Google forms to collect assignments in the form of biology test questions that had been made independently. Figure 2 depicts the appearance and features of the application.

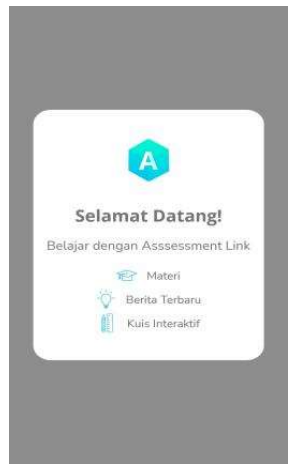

a. Assessment-Link application start page

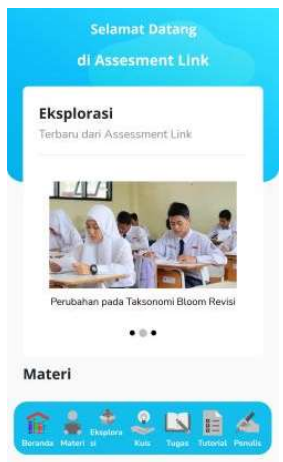

b. Home Screen

Assessment-Link application

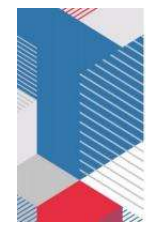

Selamat Datang di Tutorial Aplikas
Assesment Link

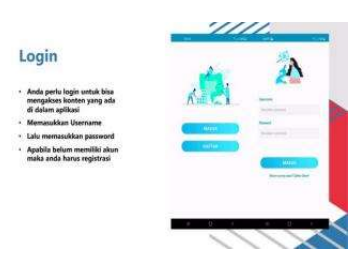

c. Assessment-Link application usage guide

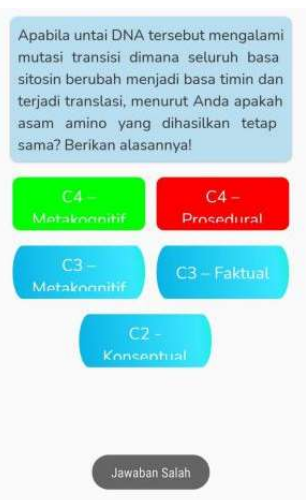

e. Assessment-Link app interactive quiz display

\section{d. Material menu in the Assessment-Link application}
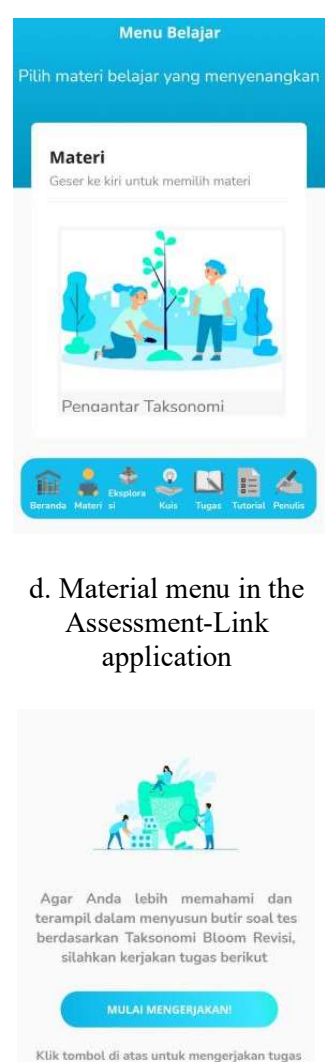

d. Task View in Assessment-Link app
Fig. 2. Assessment-Link Application Features

The application was then validated by six biology education assessment experts to determine its feasibility. Research [30] stated that it was important for a developed application having good validity and reliability. So, it was necessary to do validation in order to produce a decent application. Table 3 shows the validation results.

Table 3. Results of validity test

\begin{tabular}{|c|l|c|c|}
\hline No & Assessment Aspects & $M$ & Classification \\
\hline 1 & $\begin{array}{l}\text { Content } \\
\text { - Accuracy of } \\
\text { application features } \\
\text { in supporting } \\
\text { biology test analysis } \\
\text { skills }\end{array}$ & 3.77 & Very Good \\
$\begin{array}{l}\text { - Sufficiency and } \\
\text { coverage of } \\
\text { materials } \\
\text { Student } \\
\text { accommodation and } \\
\text { discussion }\end{array}$ & 3.81 & Very Good \\
\cline { 2 - 4 } & $\begin{array}{l}\text { Average score of } \\
\text { content aspect }\end{array}$ & 3.75 & Very Good \\
\hline 2 & $\begin{array}{l}\text { Design } \\
\text { - Platform and media }\end{array}$ & 3.83 & Very Good \\
\hline
\end{tabular}




\begin{tabular}{|c|c|c|c|}
\hline No & Assessment Aspects & $M$ & Classification \\
\hline & integration & & \\
\hline & - Screen design & $\begin{array}{l}3.83 \\
3.83\end{array}$ & Very Good \\
\hline & $\begin{array}{l}\text { - Information } \\
\text { presentation }\end{array}$ & 3.83 & Very Good \\
\hline & - Ease of use and & 3.93 & Very Good \\
\hline & - Utilities & 3.80 & Very Good \\
\hline & - Cultural sensitivity & 3.94 & Very Good \\
\hline & $\begin{array}{l}\text { Average score of } \\
\text { design aspect }\end{array}$ & 3.86 & Very Good \\
\hline 3 & Engagement & & \\
\hline & $\begin{array}{l}\text { - Learner control and } \\
\text { accessibility }\end{array}$ & 3.67 & Very Good \\
\hline & - Interactivity & 3.67 & Very Good \\
\hline & $\begin{array}{l}\text { - Interests and } \\
\text { aesthetics }\end{array}$ & 3.55 & Very Good \\
\hline & $\begin{array}{l}\text { Average score of } \\
\text { engagement aspect }\end{array}$ & 3.63 & Very Good \\
\hline & M Total & 3.78 & Very Good \\
\hline
\end{tabular}

Table 3 shows that all assessment aspects were in very good criteria, with varying average scores. The content aspect obtained an average score of 3.77 with very good criteria. This implies that the content presented in the Assessment-Link application was in accordance with the Revised Bloom's Taxonomy concept and the criteria for good question writing on each knowledge and cognitive domain as well as how to combine these two domains on a test item. The validation results also showed that the features contained in the Assessment-Link application could support the analysis skills of biology test questions based on the Revised Bloom's Taxonomy and could accommodate various types of learners and discussion activities.

The Assessment-Link application received a good validation in terms of content because in the manufacturing process it paid attention to several aspects such as application features and teaching materials needed to support biology test analysis skills. The use of applications in learning could support the mastery of certain skills if the content and features presented were in accordance with the age of the user [18].

In addition, Assessment-Link was also useful for various types of learners and the ease of user access in the manufacturing process. It was designed in the form of an android-based application that could be accessed via mobile devices to make users easier to access information anytime and anywhere. Mobile devices such as smartphones were easily accessible anytime and anywhere [31].

The validation results also showed that the Assessment-Link application might support biology teachers and pre-service teachers to discuss and study independently. The use of smartphones and applications in learning allowed them to be able to engage independently with a wide range of digital resources [32].

The design aspect obtained an average score of 3.86 with very good criteria. Research by [33] stated that design aspect was one of the main assessment criteria in determining the quality of an application. In this study, 6 sub-aspects were assessed including platform and media integration, screen design, information presentation, ease of use and navigation, utility, and cultural sensitivity. In the sub-aspects of platform and media integration, there was integration between applications and websites on the Exploration menu and was integrated with Google forms on the Tasks menu. Users could access websites that contained additional explanations regarding the revised Bloom's taxonomy through the Exploration feature.

In the sub-aspects of screen design and information presentation, the screen design was designed to be simple and used a combination of contrasting colours and clearly legible writing. The presentation of material and design that was simple, but important and meaningful will, made users more interested in learning to use android applications [34]. In the sub-aspects of ease of use and navigation, the Assessment-Link application could be accessed and installed on various types of android-based gadgets. Android was chosen because it was one of the widely used operating systems, more users would be engaged with it [8].

The Assessment-Link application could support the ability to analyse and compile biology test questions based on the revised Bloom's taxonomy. This was because the application had been equipped with materials related to the revised Bloom's taxonomy, criteria for preparing good test questions, and examples of biology test questions based on the revised Bloom's taxonomy that could be accessed by users through the Material feature. The application also used good and correct Indonesian, did not contain problems on ethnicity, religion, race, and inter-group relations, and could accommodate various ethnic and cultural backgrounds of users.

The engagement aspect obtained an average score of 3.63 with very good criteria. This showed that the Assessment-Link application paid attention to user engagement in its development. The Assessment-Link application provided flexibility of access to students by providing full access to all contents presented in the application. In addition, this application also had a high access speed so that users did not have to wait long to open a content or move to another content. However, because the application was internet-based, in unstable network conditions, application access became slower, thus the validator suggested reducing the file size. The validator also provided suggestions to add a feature called My Account, which served to personalize and check user's history.

The use of the application also had a very good interactivity value because it used the latest technology. This could provide an interesting learning experience for students. The use of android in learning could make learning process more interactive and interesting, and potentially increase learning motivation [35]. The wordings were written well and accompanied by a logo with an attractive design and in accordance with the content discussed. For example, the logo on the Material feature was like a person reading a book and the logo on the Exploration feature was like a globe. However, one 
of the validators suggested revising the logo design on the Author menu, because it was a pencil drawing, and should be replaced with an icon that would be more impressive and appealing to the user [35].

The Assessment-Link application also employed the latest technology in its development. This application was designed to be accessible via mobile devices, which became the most widely used device by the public. Data from Kominfo portrayed that the use of cellular devices in Indonesia reached 341,277,549 in 2019 [36]. This number certainly exceeded the total population of Indonesia, which was only amounted of 267 million people [36]. This indicated that some people even used more than 1 mobile device.

The Assessment-Link application was developed using android technology, which was one of the most widely used operating systems. The advantages of the Android operating system were the ease of access and interactivity offered. The validation results also showed that the Assessment-Link application provided an interesting learning experience and encouraged user interaction. An application could increase the effectiveness of learning if the application could encourage interaction with users [17]. At this time, access to the Assessment-Link application was still limited to mobile devices using the Android operating system. In future, it might cover both Android and IOS, so that more interest would be facilitated and enabled to access the Assessment-Link application.

\section{Conclusion}

In conclusion, the Assessment-Link application obtained a very good category in all aspects of the assessment which were the content, design, and engagement aspects. This conveys that the AssessmentLink application is feasible to use to prepare pre-service teachers in analysing and compiling biology test questions based on the revised Bloom's taxonomy. The application is equipped with various features that can facilitate users in learning the revised Bloom's taxonomy and how to analyze and compile good biology test questions in accordance with the revised Bloom's taxonomy.

The authors would like to thank undergraduate students of Biology Education, Universitas Negeri Surabaya, who participated in the needs analysis. They also thanked all validators who provided assessments and suggestions for the Assessment-Link application. At last, they thanked Husfina Lailiyatus Suaidah, S.Pd. dan Sonia Diana Savitri, S.Pd. who helped this study. The authors also thanked Universitas Negeri Surabaya that has funded this study.

\section{References}

[1] L. W. Anderson, D. R. Krathwohl, P. W. Airasian, K. A. Cruikshank, R. E. Mayer, P. R. Pintrich, J. Raths, M. C. Wittrock, A taxonomy for learning, teaching, and assessing; A revision of bloom's taxonomy of educational objectives
(New York: Addison Wesley Longman, Inc. (2001)

[2] Crowe, C. Dirks, M. P. Wenderoth, CBE - Life Sci Edu 7, 368-381 (2008)

[3] S. F. Kusuma, Z. A. Rinanza, Kinetik 3, 145-152 (2008)

[4] M. F. Sibo, C. O. Ocbogba, Int. J. Entr. Biz. Innov 2, 12-20 (2009)

[5] S. Diab, S. Badie, Int. J. Mngmt. Info. Tech 9 (2017)

[6] Arrorio, Prob. Edu. $21^{\text {st }}$ C 78, 309-313 (2020)

[7] S. Arabacioglu, O. U. Ayse, J. Baltic Sci. Edu 15, 216-231 (2016)

[8] H. F. El-Sofany, H. F. El-Seoud, H. M. Alwadani, A. E. Alwadani, Int. J. Interact. M. Tech 8, 4-9 (2004)

[9] M. S. Muslimin, N. M. Nordin, A. Z. Mansor, M. M. Yunus, Malay. J. Learn. Instruc: Spec. Iss, 221-255 (2017)

[10] J-H. Bae, S-K. Kim, Adv. Comp. App, 597-602 (2014)

[11] M. Astra, H. Nasbey, A. Nugraha, Eur. J. Math. Sci. Tech. Edu 11, 1081-1088 (2015)

[12] F. S. Arista, H. Kuswanto, Int. J. Instruc 11, 1-16 (2017)

[13] S. Kocakoyun, H. Bicen, Cypriot J. Edu. Sci 12, 58-68 (2017)

[14] K. Behera, Int. J. N. Trend Edu. Impl 4, 24-34 (2013)

[15] Y. T. Sung, K. E. Chang, T. C. Liu, Comp. \& Edu 94, 252-275 (2016)

[16] K. T. Martono, D. N. Oky, Int. J. Comp. Sci. Iss 11, 168-174 (2014)

[17] J. Zahorec, A. Haskova, M. Bilek. J. Baltic Sci. Edu 13, 361-380 (2014)

[18] K. Storey, C. Minner (Systematic instruction of functional skills for students and adults with disabilities, Springfield: Charles C. Thomas Publisher, (2011)

[19] K. L. Lubniewski, C. L. McArthur, W. Harriott, Int. Elec. J. Elem. Edu 10, 323-329 (2018)

[20] P. Weng, T. Taber-Doughty, J. Spec. Edu. Tech 30, 43-58 (2015)

[21] E. Furst (Bloom's Taxonomy: A Forty-Year Retrospective, Chicago: The National Society forthe Study of Education, (1994)

[22] Amer, Elec. J. Res Edu. Psyc 8, 213-230 (2006)

[23] Ari, Edu. Sci: Theor. \& Prac 11, 767-772 (2011)

[24] Rahayu, Eur. J. Multidiscip. Studies 7, 80-85 (2018)

[25] S. A. Rahman, F. A. M. Nor, Eng. Lang. Teach 10, 245-256 (2017)

[26] G. R. Morrison, S. M. Ross, G. E. Kemp, Component of the instructional design plan, 12, Designing effective instruction, $7^{\text {th }}$ edition, John Wiley \& Sons, Inc. (2013)

[27] C-Y. Lee, T. S. Cherner, J. Infor. Tech. Edu: Res 14, 21-53 (2015)

[28] N. Tambunan, F. A. Batubara, Int. J. Res. Rev 7, 542-547 (2020)

[29] I. Fauzi, Globis, Eng-Ind J. Eng. Edu. Cult 6, 3243 (2018) 
[30] A.G. Silva, P. Simoes, A. Queiros, M. Rodrigues, N. P. Rocha, J. Med. Syst 44, (2020)

[31] H. Crompoton, D. Burke, Comp. \& Edu. 123, 5364 (2018)

[32] M. L. Bernacki, J. A. Greene, H. Crompton, Cont. Edu. Psy 60, 1-34 (2020)

[33] R. Nouri, S. R. N. Kalhori, M. Ghazisaeedi, G. Marchand, M. Yasini, J. Am. Med. Inf. Assoc 25, 1089-1098 (2018)

[34] Abildinova, M. Gulmira, Int. J. Envi. \& Sci. Edu 11, 5128-5245 (2016)

[35] ANovitasari, Lisdiana, A. Marianti, J. Innov. Sci. Edu 10, 70-78 (2021)

[36] Sub Direktorat Statistik Komunikasi dan Teknologi Informasi, Statistik Telekomunikasi Indonesia 2019 (Jakarta: Badan Pusat Statistika, (2019) 